\title{
What are the consequences of fish entrainment and impingement associated with hydroelectric dams on fish productivity? A systematic review protocol
}

Trina Rytwinski ${ }^{1,2,3^{*}}$, Dirk A. Algera ${ }^{1,2}$, Jessica J. Taylor ${ }^{1,2}$, Karen E. Smokorowski ${ }^{4}$, Joseph R. Bennett ${ }^{2,3}$, Philip M. Harrison ${ }^{1,5}$ and Steven J. Cooke ${ }^{1,2}$

\begin{abstract}
Background: This systematic review will address the need for a better understanding of the impacts of fish entrainment and impingement associated with hydroelectric dams on fish productivity in freshwater temperate environments. As the number of dams continues to increase worldwide, so too has concerns for their effects on fish populations. Fish injury and mortality at hydroelectric facilities may have serious consequences for fish populations, which are generally the result of three main sources: (1) fish passage through hydroelectric facilities (i.e., turbines, spillways, sluiceways, and other passage routes) during downstream migration for migratory fish; (2) the entrainment of resident fish; and (3) the impingement of fish (migratory or resident) against screens/trash racks. Most studies on the impacts of entrainment and impingement at hydroelectric facilities on fish have primarily focused on: (1) how fish injury and mortality occurs; and (2) evaluations of the effectiveness of various management strategies used to mitigate harm during downstream passage. Given the contributions of migratory and resident adults and juveniles to fish production, a necessary extension is to evaluate the impacts of fish injury and mortality from hydropower dam entrainment and impingement on fish productivity. Therefore, to ensure the sustainability of fishes dependent on our freshwater ecosystems, a better understanding of the impacts of fish entrainment and impingement associated with hydroelectric dams on fish productivity is needed.
\end{abstract}

Methods: This systematic review will search for, compile, summarize and synthesize evidence on the impacts of fish entrainment and impingement associated with hydroelectric dams on fish productivity in freshwater temperate environments. Considered studies will include (but not be limited to): (1) those that report a metric related to mortality and injury as an indication of the effect on fish productivity; (2) the change in a metric related to mortality and injury relative to an appropriate control; and (3) articles that scale-up the evaluation to include some estimate of a change in a component of fish productivity (e.g., articles that include an estimate of fish loss from the population due to entrainment/impingement by comparing a metric related to mortality or injury to an estimate of population size or biomass). Only studies where the causal relationship between intervention and outcome is made clear to allow for the effects of entrainment and impingement to be isolated from other potential impacts of hydroelectric power production (e.g., barriers to migration and/or habitat degradation), will be included. The review will use public search engines and specialist websites, and will include both primary and grey literature. Potential effect modifiers will be identified to obtain a better understanding of the factors that are associated with variation in effects among studies,

\footnotetext{
*Correspondence: trytwinski@hotmail.com

${ }^{2}$ Canadian Centre for Evidence-Based Conservation and Environmental

Management, Institute of Environmental Sciences, Carleton University,

Ottawa, ON, Canada

Full list of author information is available at the end of the article
} 
given differences in: (1) site-specific factors (e.g., turbine type, size, power output); (2) methodologies and study designs used to assess impacts; and (3) biological factors (e.g., fish life history stage, body size and morphology). Study quality will be assessed to allow for critical evaluation, including study design, confounding factors and statistical analysis. Data will be compiled into a narrative synthesis and a meta-analysis will be conducted where data availability and quality allow.

Keywords: Dam, Evidence-based policy, Fish biomass, Fish abundance, Fish density, Fish migration, Fish survival, Hydropower, Reservoirs

\section{Background}

Worldwide over 58,000 dams ( $>15 \mathrm{~m}$ height) have been constructed for various uses including irrigation, flood control, navigation, and hydroelectric power generation [1]. As the number of dams continues to increase worldwide, so too has concerns for their effects on fish populations. Dams can act as a barrier to migratory (i.e., anadromous, catadromous, potamodromous) and resident fish (i.e., those that complete their life cycle within a reservoir or section of the river), fragmenting rivers and degrading habitats. The negative impacts of dams on upstream migration of diadromous fish are widely acknowledged, and the installation of various types of fishways to facilitate upstream passage are commonplace [2]. However, downstream migration of fish at dams remains a challenge [3,4]. Depending upon the natural history of a given migratory fish, mature adults seeking spawning grounds (e.g., catadromous species) or juveniles or post-spawn adults (for iteroparous species) seeking rearing and feeding habitats (e.g., anadromous species) may all need to move downstream past dams. Resident species may also move considerable distances throughout a riverine system for reproduction, rearing, and foraging (e.g., Kokanee salmon Oncorhynchus nerka; white sucker Catostomus commersonii; walleye Sander vitreus) or simply move throughout reservoirs where they may traverse forebay areas.

Fish injury and mortality resulting from entrainment or impingement associated with hydroelectric facilities may have serious consequences for fish populations $[5,6]$. Sources of entrainment or impingement-related injury or mortality include the following: (1) fish passage through hydroelectric facilities (i.e., turbines, spillways, sluiceways, and other passage routes) during downstream migration for migratory fish; (2) the entrainment of resident fish; and (3) the impingement of adult or large fish (migratory or resident) against screens/ trash racks. Migrating fish will use existing dam structures such as spillways and outlet works, used to release and regulate water flow, for downstream passage. When no spills occur owing to low reservoir water levels, both resident and facultative migrant fish can be attracted to the turbine intake tunnels, often the only other source of downstream flow present in the forebay area of the dam. Entrainment, occurring when fish travel through a hydro dam to the tailraces, can result in physical injury and mortality from fish passing through turbines and associated components $[6,7]$. Injury and mortality can occur through several means from hydroelectric components. Freefall from passing over a spillway, abrasions, scrapes, and mechanical strikes from turbine blades are well known causes of physical injury and mortality (reviewed in [6-8]). Injuries from turbulence and shear owing to different water velocity experienced across the body length, occurs when passing over a spillway or through turbine components [9]. Water pressure associated injuries and mortality can occur from low pressure, rapid changes in pressure, shear stress, turbulence, cavitation (extremely low water pressures that cause the formation of bubbles which subsequently collapse violently), strike, or grinding when fish become entrained in turbine components $[5,10,11]$. Injury and mortality can also occur from fish being impinged against screens or trash racks that are intended to prevent debris, or in some cases fish, from being drawn into water intakes [12].

Since downstream migrants are not often observed (e.g., juvenile fish), historically far less consideration has been afforded to downstream passage, such that management strategies and/or structures specifically designed to accommodate downstream passage were not implemented nearly as frequently [13]. To date, literature on downstream passage largely focuses on juvenile survival, particularly in Pacific salmonids (Oncorhynchus spp.), popular commercial and recreational species in which the adults senesce after spawning. Minimal research exists on downstream passage and entrainment risk of resident fish species [8]. However, research on adult downstream passage in migratory fish is growing in popularity in temperate Europe and North America, particularly for species of conservation interest such as eels (Anguilla spp., [14-19]) and sturgeons (Acipenser spp., [20-22]). To enhance downstream passage and reduce mortality, management strategies have included selectively timing spills to aid juvenile fish, the installation of "fish friendly" by-pass systems and screens directing fish to these systems, and retrofitting dams with low-volume surface flow 
outlets [23] or removable spillway structures designed to minimize fish harm [24]. The use of light, sound, bubble curtains, and electrical currents to act as repellent from harmful paths or potentially an attractant to more desirable (fish friendly) paths have been explored [25]. Given that the timing of downstream migration differs among life stages and is species-dependent [8], mitigating injury and mortality during downstream passage in a multispecies system could prove challenging and disruptive to power generation operations. Furthermore, operational strategies can be complicated by environmental regulations such as water quality requirements.

From a fish productivity perspective, minimizing impacts during downstream passage for migratory fish, unintended entrainment of resident species, and/or fish impingement, is an integral part of managing fish productivity. Downstream passage mortality from a single hydropower dam may appear low (i.e., 5-10\%), but system-wide cumulative mortalities may be considerable in systems greatly fragmented by multiple dams [26]. Adult survival affects population dynamics (e.g., effective population size), and thus fisheries yields (e.g., sustainable yield, maximum sustainable yield). Juvenile survival affects recruitment (i.e., fish reaching an age class considered part of a fishery), ultimately contributing to fisheries productivity. Literature reviews and technical reports compiled to date primarily focus on how fish injury and mortality occurs, and/or evaluate the effectiveness of various management strategies used to mitigate harm during downstream passage [6-8]. Given the contributions of migratory and resident adults and juveniles to fish production, a natural extension would be evaluating the impacts of fish injury and mortality from hydropower dam entrainment and impingement on fish productivity. Systematic reviews and meta-analyses can be valuable tools to (1) reveal generalized relationships between the impacts of fish entrainment and impingement and fish productivity; (2) summarize the various research methods and study designs for studying such relationships; and (3) identify knowledge gaps and future research directions.

\section{Advisory team input}

During the formulation of the question for this review, an Advisory Team made up of stakeholders and experts was established and consulted. This team included academics, staff from the Oak Ridge National Laboratory (U.S. Department of Energy), and staff from Fisheries and Oceans Canada (DFO), specifically the Fisheries Protection Program (FPP), and DFO Science Branch. The Advisory Team guided the focus of this review to ensure the primary question was both answerable and relevant, and suggested search terms to capture the relevant literature. The Advisory Team was also consulted in the development of the inclusion criteria for article screening and the list of specialist websites for searches.

\section{Objective of the review}

The objective of the systematic review is to evaluate the existing literature base to determine the consequences of fish entrainment and impingement associated with hydroelectric dams on fish productivity in freshwater temperate environments.

\section{Primary question}

What are the consequences of fish entrainment and impingement associated with hydroelectric dams on freshwater fish productivity in temperate regions?

\section{Components of the primary question}

The primary study question can be broken down into the study components:

Population: Freshwater fish, including diadromous species, in temperate regions.

Intervention: Infrastructure associated with hydroelectric facilities (i.e., turbines, spillways, sluiceways, outlet works, screens, tailraces, water bypasses, tailwaters, penstocks, trash racks, draft tubes).

Comparator: No intervention or modification to intervention.

Outcomes: Change in a component of fish productivity (broadly defined in terms of: mortality, injury, biomass, yield, abundance, diversity, growth, survival, individual performance, migration, reproduction, population sustainability, and population viability).

\section{Methods}

Searches

\section{Search terms}

A list of relevant search terms was generated by the Advisory Team, and divided into three components: the population (subject and environment type), intervention and outcome, and will be combined using Boolean operators "AND" and/or "OR" (Table 1).

The asterisk (") is a wildcard and represents any characters, including no character (e.g., Spill* includes spill, spilling, spills, spilled) while the dollar sign (\$) includes zero or one character (e.g., Reservoir\$ includes reservoir or reservoirs). Since it was not feasible to include every possible relevant species name, the broad search term "fish" was included in an attempt to capture studies of every relevant species. While this could potentially exclude articles that do not contain the word 'fish' in the title/abstract/keywords, we were confident that our searches would still find relevant articles because some of the databases/search engines (e.g., Science.gov and Google scholar) search the full record for terms 
Table 1 Proposed search string for the execution of the search strategy

\begin{tabular}{|c|c|}
\hline Component & Search string \\
\hline \multirow[t]{2}{*}{ Population terms } & $\begin{array}{l}\text { (Fish* AND (Reservoir\$ OR Impoundment\$ OR } \\
\text { Dam\$ OR "Hydro electric*" OR Hydroelectric* OR } \\
\text { "Hydro dam*" OR Hydrodam* OR "Hydro power" } \\
\text { OR Hydropower OR"Hydro")) }\end{array}$ \\
\hline & AND \\
\hline \multirow[t]{2}{*}{ Intervention terms } & $\begin{array}{l}\text { (Turbine\$ OR Spill* OR Outlet* OR Overflow* OR } \\
\text { Screen\$ OR Tailrace\$ OR “Tail race" OR Diversion OR } \\
\text { Bypass* OR Tailwater\$ OR Penstock\$ OR Entrain* } \\
\text { OR Imping* OR Blade\$ OR Intake\$ OR "Trash rack\$" } \\
\text { OR "Draft tube\$") }\end{array}$ \\
\hline & AND \\
\hline Outcome terms & $\begin{array}{l}\text { (Productivity OR Growth OR Performance OR Surviv* } \\
\text { OR Success OR Migrat* OR Passag* OR Reproduc* } \\
\text { OR Biomass OR Stress* OR Mortalit* OR Abun- } \\
\text { dance\$ OR Densit* OR Yield\$ OR Injur* OR Viability } \\
\text { OR Sustainability OR “Vital rate\$" OR Persistence OR } \\
\text { "Trauma") }\end{array}$ \\
\hline
\end{tabular}

(not optional), increasing the chance that 'fish' would be selected. Furthermore, additional targeted searches will be conducted to locate articles that have not been found using this search strategy, including: (1) website searches, (2) hand searching reference sections of included articles and reviews to evaluate relevant titles, symposium papers and other articles, and (3) evidence calls to the broader scientific community via social media and email to help locate research articles that are difficult to obtain, or for suggestions of articles to include (see Specialist websites and Other literature searches below for additional details).

\section{Abbreviated search}

When a complex search string is not accepted by the search engine, the help menu will be consulted and the search terms will be modified. The search terms will be recorded in the article databases in order to preserve all metadata associated with the search.

\section{Article type}

The search will include a variety of article types, including primary literature in peer-reviewed journals and grey literature. The search strategy will strive to minimize publication biases by focusing efforts equally on each article type, and all articles will be equally critically appraised to ensure validity.

\section{Document/file formats}

The search will not have any document type restrictions (e.g., PDF vs. PowerPoint vs. MS-Word). All formats will be acquired and if specialized software is required, alternative formats will be requested for ease of file transferability. Where books are identified, digital copies will be sought (either through internet searches for availability or requests to authors) in order to ensure that all obtainable records are made available as an output from this review.

\section{Computer settings}

The browsing history and cookies will be disabled on all computers used to conduct the search. The members of the Review Team will not access any electronic accounts (e.g., email, website) during the search period and will use "private mode" (Safari) for web browsers to reduce the possibility of user-specific search results.

\section{Language}

English search terms will be used to conduct all searches in all databases. All references that are returned will be included in the database. When articles in other languages are returned using the search strategy, those records will be reported in the database.

\section{Publication databases}

The following online databases will be searched.

1. Waves (Fisheries and Oceans Canada)-Canadian government books, reports, government documents, theses, conference proceedings and journal titles

2. ProQuest Dissertations \& Theses Global-Collection of dissertations and theses from around the world, spanning from 1743 to the present

3. Science.gov-U.S. Federal Science

4. ISI Web of Science Core Collection-Multidisciplinary research topics including journals, books, proceedings, published data sets and patents

5. Scopus-Abstract and citation database of peerreviewed literature including journals, books and conference proceedings.

\section{Search engines}

Search terms will be entered into Google Scholar and the first 500 hits (sorted by relevance) will be screened for the appropriate fit for the review questions.

\section{Specialist websites}

Specialist organization websites listed below will be searched using connectors created in Import.io and abbreviated search terms [i.e., search strings (1) fish AND hydro AND entrainment; (2) fish AND hydro AND impingement; (3) fish AND hydro AND mortality; and (4) fish AND hydro AND injury]. Page data from the first 20 search results for each search string will be extracted, screened for relevance, and searched for links or references to relevant publications and data and grey 
literature. The list of websites was narrowed to the following 29 organizations after consulting with our Advisory Team for relevance.

1. Alberta Hydro

2. British Columbia Hydro

3. Centre for Ecology and Hydrology

4. Centre for Environment, Fisheries and Aquaculture Science

5. Commonwealth Scientific and Industrial Research Organisation (CSIRO)

6. Electric Power Research Institute

7. EU water framework directive

8. Federal Energy Regulatory Commission

9. Fisheries and Oceans Canada

10. Fisheries Research Service

11. Food and Agriculture Organization of the United Nations

12. Hydro Québec

13. Land and Water Australia

14. Manitoba Hydro

15. Ministry of Natural Resources and Environment of the Russian Federation

16. Ministry of the Environment New Zealand

17. National Institute of Water and Atmospheric Research New Zealand

18. Natural Resources Canada

19. Natural Resources Wales

20. Newfoundland and Labrador Hydro

21. National Institute of Water and Atmospheric Research

22. Northern Ireland Environment Agency

23. Office of Scientific and Technical Information (U.S. Department of Energy)

24. Pacific Fisheries Environmental Laboratory

25. Parks Canada

26. The Nature Conservancy

27. Trout Unlimited

28. United Nations Environment Programme

29. US Fish and Wildlife Service

\section{Other literature searches}

Reference sections of accepted articles will be hand searched to evaluate relevant titles, symposium papers and other articles that have not been found using the search strategy. Authors of any unpublished references will be contacted to request access to the full article. Stakeholders will be consulted for insight and advice for new sources of information.

The Review Team will contact authors of unobtainable articles in an attempt to gain access to the full article. We will also use social media and email to alert the community of this systematic review and to reach out to area experts for research articles that are difficult to obtain, or for suggestions of articles to include. Any article provided will also be used to test the comprehensiveness of our search strategy and, where appropriate, adjustments will be made to the search strategy to ensure it is comprehensive and inclusive. Any changes made to the search strategy will be justified and documented in the final review document.

\section{Search record database}

All articles generated by each of the search strategies will be exported into separate Zotero databases. After all searches have been completed and references found using each different strategy have been compiled, the individual databases will be exported into EPPI-reviewer as one database. Duplicates will be identified and merged. All references regardless of their perceived relevance to this systematic review will be included in the database. This database will act as the archive and will remain unchanged throughout the review process, since it is the direct product of the search strategy and will be useful in the future when updating the systematic review archive (general updating timeframe is currently every 5 years).

\section{Article screening and study inclusion criteria Screening process and inclusion criteria}

Articles found using the search criteria will be screened in two distinct stages: (1) title and abstract, and (2) full text. Before the screening of title and abstracts begins, two reviewers using a subset of $10 \%$ of all articles or 100 abstracts (whichever is bigger) will undertake consistency checks to ensure consistent and repeatable decisions are being made in regards to which articles get screened out and which go on in the process to be further reviewed. The two reviewers will use a Kappa test to determine consistencies in screening decisions. A Kappa score of $\geq 0.6$ indicates substantial agreement between reviewers and will be required to be achieved before any further screening is conducted for the review. The results from the consistency check will be discussed and discrepancies will be reviewed by both reviewers to understand why the choice was made to include/exclude the article. This same process will be repeated prior to screening articles at full text i.e., two reviewers using a subset of $10 \%$ of all articles that were included at title and abstract, will undertake consistency checks and a Kappa score of $\geq 0.6$ will be required before any further screening is conducted.

All article screening decisions will be included in the database, so it will be clear at what level any article was excluded. If the decision to include or exclude a specific article is unclear, that article will be retained and will go on to the next level of screening. If there is further doubt, the Review Team will discuss those articles as a group to 
come up with a decision. Any articles that do not have abstracts (as is the case for some grey literature), those articles will automatically be screened at the full text level. Justification of the reason for inclusion or exclusion of an article will be explained and recorded using EPPI reviewer, and all articles excluded at the full text level will be included with the review, in compliance with CEE guidelines [27]. Only English-language literature will be included during the screening stage.

Articles will be excluded based on the following predefined inclusion criteria developed in consultation with the Advisory Team:

\section{Relevant subjects}

Any fish species, including diadromous species, in North $\left(23.5^{\circ} \mathrm{N}-66.5^{\circ} \mathrm{N}\right)$ or South $\left(23.5^{\circ} \mathrm{S}-66.5^{\circ} \mathrm{S}\right)$ temperate regions. Only studies located in freshwater ecosystems, including lakes, rivers, and streams that contain fish species that are associated with a hydroelectric dam system will be included.

\section{Relevant interventions}

Articles that describe infrastructure associated with hydroelectric facilities that may cause fish to be entrained or impinged (i.e., turbines, spillways, sluiceways, outlet works, screens, tailraces, water bypasses, tailwaters, penstocks, trash racks, draft tubes etc.). Only articles that describe water that moves via gravity will be included. Studies will be excluded where water is actively pumped for: (1) power generation (e.g., storage ponds: Robbins 1976); (2) irrigation; or (3) cooling-water in-take structures for thermoelectric power plants. Other studies excluded describe infrastructure associated with other operations: (1) nuclear facilities; (2) dams without hydro; (3) hydrokinetic systems (i.e., energy from waves/ currents); or (4) general water withdrawal systems (e.g., for municipal drinking, recreation, etc.).

\section{Relevant comparators}

Relevant comparators will include: (1) before intervention data within same waterbody (i.e., pre-installation/ modification); (2) no intervention (e.g., control experiments whereby each phase of a test procedure is examined for sources of mortality/injury other than passage through infrastructure e.g., mortality attributable to upstream introduction and/or downstream recovery apparatus while turbine is operating but no fish passage through turbine); (3) an unmodified version of the intervention on the same or different study waterbody, or (4) controlled flume study.

\section{Relevant outcomes}

Most metrics used to evaluate consequences of fish entrainment and impingement will be related to fish mortality and injury. Any article that uses a metric related to: (1) lethal impact: direct fish mortality or indirect mortality (e.g., fish are disoriented after passage through hydroelectric dam and then predated upon), and (2) sublethal impacts: external and/or internal injury assessments (e.g., signs of scale loss, barotrauma, blade strike, etc.) - will be included. These metrics can include, but not limited to, reported mortality rate (\%), survival rate (\%), injury rate (\% of population) with particular types of injuries (e.g., signs of blade strike) or all injury types combined.

To evaluate the impact of fish mortality/injury from entrainment and impingement for fish productivity, the reported measured effect should indicate some change in a component of fish productivity. We will use a broad definition of fish productivity to include any measurement related to: mortality, biomass, abundance, yield, diversity, growth, survival, migration, reproduction, population viability, sustainability, persistence, stress, injury, trauma, or surrogate thereof. In many situations, the effect for fish productivity will be the reported metric related to mortality and injury, or the change in these metrics relative to the control. However, we will also include articles that scale-up the evaluation to include some estimate of a change in a component of fish productivity. For example, articles that include an estimate of fish loss from the population due to entrainment/impingement by comparing a metric related to mortality or injury to an estimate of population size, will be included. Therefore, if the article evaluates mortality/injury (e.g., \% mortality) and also scales-up the evaluation by using either (1) population estimates upstream of the dam based on field collected data (e.g., hydroacoustic sampling, electrofishing, etc.), or (2) some form of modeling (e.g., individual-based simulation models or population viability analysis), these will be included.

Furthermore, the causal relationship between intervention and outcome should be made clear to allow for the effects of fish mortality/injury from entrainment and impingement to be isolated from other potential impacts of hydroelectric power production such as barriers to migration and/or habitat degradation. Studies where no clear mechanism is identified (e.g., if fish density is surveyed up-and down-stream of a hydro dam but any difference or change in fish density cannot be clearly linked to impingement or entrainment in isolation of other effects) will be excluded.

\section{Relevant types of study design}

Study designs with appropriate comparators including Before/After (BA), Control/Impact (CI), as well as studies combining these types of comparisons, Before/After/ Control/Impact (BACI) and Randomized Controlled 
Trials (RCT) will be included. Review papers and policy discussions will be excluded.

\section{Study quality assessment}

Each of the studies that make it to the full text screening level will be classified and coded in the article database using a number of parameters including (but not limited to):

- Study setting-field or Lab

- Study design-BA/CI/BACI/RCT

- Temporal extent of study-before monitoring, after monitoring, and total duration

- Replication-replicated or unreplicated (i.e., in time and/or space)

- Randomization-randomized or not (i.e., outcome assessed using randomized methods)

- Confounding factors-present, not present, unclear, and whether they were accounted for in the study (e.g., mortality from turbines vs. mortality from recovery nets)

- Clarity of objectives in relation to methods used

- Use of (and number of) controls

- Effort devoted to assessing a change in fish productivity

- Statistical methods used in assessment of impacts of impingement/entrainment mortality on fish productivity (e.g., were results analysed statistically?)

- Statistical power of methods reported (i.e., was a power analysis conducted and results thereof reported?)

- Accounting for and/or identifying potential effect modifiers (see list in following sections).

Bilotta et al. [28] have outlined criteria for the assessment of the internal validity of a study. Their assessment criteria have been adapted from the Cochrane Collaboration's Risk of Bias Tool [29] for use in the field of environmental science. The assessment criteria include assessing selection bias, attrition bias, reporting bias, as well as criteria relevant to our study (e.g., duration of monitoring, endpoints). The criteria outlined in Bilotta et al. [28] will be used by the Review Team for this review and included in the reference database. The information for each article retrieved using the search strategy will be uniquely coded based on the criteria (generally categorised as "low risk", "high risk", or "unclear risk") to help assess the quality of each article, and to provide insight into any potential risk of bias present in each of the studies. This information will be instrumental in helping to determine reliability of the evidence base available for potentially conducting a meta-analysis on the impacts of turbine and spillway mortality on fish productivity.

\section{Data extraction strategy}

Meta-data will be extracted from the included studies by the Review Team and will be recorded in a MS-Excel database that will be made available with the published systematic review article, as additional supporting files. The extracted information will be used to assess the overall effect of fish entrainment and impingement associated with hydroelectric dams on fish productivity, and when sufficient, good quality data exist, the information will be used in a meta-analysis. Some of the outcome data that will be recorded will include: outcome means, measures of variation (e.g., standard deviation, standard error, confidence intervals), and sample sizes. When data are presented in tables or graphs, all information will be extracted and recorded. If it is not possible to decipher information from graphs, the main contact author for the article will be contacted (via email or phone) by the Review Team to request the information. During that request, the Review Team will also solicit the author to suggest any grey literature that they may know of related to the systematic review topic. Where only raw data are provided in the article, the Review Team will calculate summary statistics. In those instances, we will record how the calculations were conducted and with what information. To ensure that data is being extracted in a consistent and repeatable manner, two reviewers will extract information from 10 of the same articles. Afterwards, the information will be compared. Any inconsistencies will be discussed amongst the Review Team members, and if any disagreement occurs, they will be discussed with the entire Review Team to ensure all reviewers are extracting and interpreting data in the same manner.

\section{Potential effect modifiers and reasons for heterogeneity}

Potential effect modifiers will be identified to obtain a better understanding of the factors that are associated with variation in effects among studies, given different: (1) site-specific factors (e.g., turbine type, size, power output); (2) methodologies and study designs used to assess impacts, and (3) biological factors (e.g., fish life history stage, body size and morphology). The Review Team will extract data on potential effect modifiers from articles that are included at the full-text level of screening. All information will be recorded in the MS-Excel database. The following list is not exhaustive, but includes potential effect modifiers and reasons for heterogeneity which will be recorded where available. Further factors will be identified, defined and included throughout the process, through consultation with the Advisory Team.

- Study location

- Environment type

- Lowest taxonomical level of subject 
- Life history stage and strategy

- Fish body size/morphology

- Study design

- Monitoring duration

- Intervention type

- Turbine type/size

- Spillway type

- Comparator type

- Sampling method

\section{Data synthesis and presentation}

A narrative synthesis of data from all articles included in the systematic review will be generated. The synthesis will aim to be as visual as possible, summarizing information in tables and figures. The ultimate goal of this review is to reveal generalised relationships between the impacts of fish entrainment and impingement and fish productivity and to identify study design and methodological factors associated with these relationships. The findings of this systematic review will help to inform evidence-based management and conservation activities for resource managers that deal with maintaining fish productivity in freshwater ecosystems. All efforts will be made to provide quantitative assessments and meta-analysis of the articles included in this review, when the study designs and evidence-base allow. In the case that meta-analysis is possible (given a sufficient sample size of studies), study effect sizes will be standardized and weighted appropriately, and analysis will take the form of random-effects models. Depending on the availability of the data, metaregressions or subgroup analyses of categories of studies will also be performed. Publication-bias and sensitivity analysis will be carried out where possible. Overall effects will be presented visually in plots of mean effect sizes and variance.

\section{Authors' contributions}

The manuscript was drafted by TR and DAA. JJT, KES, JRB, PMH, and SJC provided comments and revisions. All authors read and approved the final manuscript.

\section{Author details}

${ }^{1}$ Fish Ecology and Conservation Physiology Laboratory, Department of Biology, Carleton University, Ottawa, ON, Canada. ${ }^{2}$ Canadian Centre for Evidence-Based Conservation and Environmental Management, Institute of Environmental Sciences, Carleton University, Ottawa, ON, Canada. ${ }^{3}$ Department of Biology and Institute of Environmental Science, Carleton University, Ottawa, ON, Canada. ${ }^{4}$ Great Lakes Laboratory for Fisheries and Aquatic Sciences, Fisheries and Oceans Canada, Sault Ste. Marie, ON, Canada. ${ }^{5}$ Department of Biology, University of Waterloo, Waterloo, ON, Canada.

\section{Acknowledgements}

The authors would like to thank several reviewers and collaborators who provided valuable insights to strengthen this review protocol including: Mike Power (University of Waterloo, CA), Mark Bevelhimer (Oak Ridge National Laboratory, USA), and Fisheries and Oceans Canada staff including Richard Janusz, Keith Clarke, Eva Enders, David Gibson. We also thank the reviewers for their constructive comments.
Competing interests

The authors declare that they have no competing interests.

Funding

The study was primarily supported by Fisheries and Oceans Canada. Additional support is provided by the Natural Science and Engineering Research Council of Canada, The Canada Research Chairs Program, and Carleton University.

Received: 30 November 2016 Accepted: 20 March 2017

Published online: 03 April 2017

\section{References}

1. International Commission on Large Dams (ICOLD). Register of Damsgeneral synthesis. (2015). http://www.icold-cigb.net/GB/World_register/ general_synthesis.asp. Accessed 24 Nov 2016.

2. Bunt CM, Castro-Santos T, Haro R. Performance of fish passage structures at upstream barriers to migration. River Res Appl. 2012;28:457-78.

3. Calles O, Karlsson S, Hebrand M, Comoglio C. Evaluating technical improvements for downstream migrating diadromous fish at a hydroelectric plant. Ecol Eng. 2012;48:30-7.

4. Buysse D, Mouton AM, Baeyens R, Coeck J. Evaluation of downstream migration mitigation actions for eel at an Archimedes screw pump pumping station. Fish Manag Ecol. 2015;22:286-94.

5. Čada G. The development of advanced hydroelectric turbines to improve fish passage survival. Fisheries. 2001;26:14-23.

6. Electric Power Research Institute (EPRI). Fish passage through turbines: application of conventional hydropower data to hydrokinetic technologies. Final Rep. 2011;1024638:1-40.

7. Čada GF, Coutant CC, Whitney RR. Development of biological criteria for the design of advanced hydropower turbines. Washington: EERE Publication and Product Library Department of Energy; 1997. p. 1-85.

8. Larinier M, Travade F. Downstream migration: problems and facilities. Bull Fr Pêche Piscic. 2002;364(suppl):181-207.

9. Čada G, Loar J, Garrison L, Fisher R Jr, Neitzel D. Efforts to reduce mortality to hydroelectric turbine-passed fish: locating and quantifying damaging shear stress. Environ Manag. 2006;37:898-906.

10. Čada G, Ahlgrimm J, Bahleda M, Bigford T, Stavrakas SD, Hall D, Moursund $R$, Sale M. Potential impacts of hydrokinetic and wave energy conversion technologies on aquatic environments. Fisheries. 2007;32:174-81.

11. Brown RS, Colotelo AH, Pflugrath BC, Boys CA, Baumgartner LJ, Deng D, Silva LGM, Brauner CJ, Mallen-Cooper M, Phonekhampeng O, Thorncraft $\mathrm{G}$, Singhanouvong D. Understanding barotrauma in fish passing hydro structures: a global strategy for sustainable development of water resources. Fisheries. 2014;39:108-22.

12. Barnthouse $L W$. Impacts of entrainment and impingement on fish populations: a review of the scientific evidence. Environ Sci Policy. 2013;31:149-56.

13. Katopodis C, Williams JG. The development of fish passage research in a historical context. Ecol Eng. 2012;48:8-18.

14. Jansen HM, Winter HV, Bruijs MCM, Polman HJG. Just go with the flow? Route selection and mortality during downstream migration of silver eels in relation to river discharge. ICES J Mar Sci. 2007;64:1437-43.

15. Carr JW, Whoriskey FG. Migration of silver American eels past a hydroelectric dam and through a coastal zone. Fish Manag Ecol. 2008;15:393-400.

16. Travade F, Larinier M, Subra S, Gomes P, De-Oliveira E. Behaviour and passage of European silver eels (Anguilla anguilla) at a small hydropower plant during their downstream migration. Knowl Manag Aquat Ecosyst. 2010;398(01):1-19.

17. Besson ML, Trancart T, Acou A, Charrier F, Mazel V, Legault A, Feunteun E. Disrupted downstream migration behaviour of European silver eels (Anguilla anguilla, L.) in an obstructed river. Environ Biol Fish. 2016;99:779-91.

18. Eyler SM, Welsh SA, Smith DR, Rockey MM. Downstream passage and impact of turbine shutdowns on survival of silver American eels at five hydroelectric dams on the Shenandoah River. Trans Am Fish Soc. 2016;145:964-76. 
19. Haro A, Watten B, Noreika J. Passage of downstream migrant American eels through an airlift-assisted deep bypass. Ecol Eng. 2016;91:545-52.

20. Acolas ML, Rochard E, Le Pichon C, Rouleau E. Downstream migration patterns of one-year-old hatchery-reared European sturgeon (Acipenser sturio). J Exp Mar Biol Ecol. 2012;430-431:68-77.

21. McDougall CA, Blanchfield PJ, Peake SJ, Anderson WG. Movement patterns and size-class influence entrainment susceptibility of lake sturgeon in a small hydroelectric reservoir. Trans Am Fish Soc. 2013;142:1508-21.

22. McDougall CA, Anderson WG, Peake SJ. Downstream passage of lake sturgeon through a hydroelectric generating station: route determination, survival, and fine-scale movements. N Am J Fish Manag. 2014;34:546-58

23. Johnson GE, Dauble DD. Surface flow outlets to protect juvenile salmonids passing through hydropower dams. Rev Fish Sci. 2006;14:213-44.

24. Adams NS, Plumb JM, Perry RW, Rondorf DW. Performance of a surface bypass structure to enhance juvenile steelhead passage and survival at Lower Granite Dam, Washington. N Am J Fish Manag. 2014;34:576-94.
25. Popper AN, Carlson TJ. Application of sound and other stimuli to control fish behavior. Trans Am Fish Soc. 1998;127:673-707.

26. Marohn L, Prigge E, Reinhold H. Escapement success of silver eels from a German river system is low compared to management-based estimates. Freshw Biol. 2014;59:64-72

27. Collaboration for Environmental Evidence. Guidelines for systematic review and evidence synthesis in environmental management. Version 4.2. Environ Evid. 2013; http://environmentalevidence.org/wp-content/ uploads/2014/06/Review-guidelines-version-4.2-finalPRINT.pdf. Accessed 26 Jan 2017.

28. Bilotta GS, Milner AM, Boyd IL. Quality assessment tools for evidence from environmental science. Environ Evid. 2014;3:14.

29. Higgins JP, Altman DG, Gøtzsche PC, Jüni P, Moher D, Oxman AD, Sterne $J A$. The Cochran Collaboration's tool for assessing risk of bias in randomised trials. Bmj. 2011;343:d5928.

\section{Submit your next manuscript to BioMed Central and we will help you at every step:}

- We accept pre-submission inquiries

- Our selector tool helps you to find the most relevant journal

- We provide round the clock customer support

- Convenient online submission

- Thorough peer review

- Inclusion in PubMed and all major indexing services

- Maximum visibility for your research

Submit your manuscript at www.biomedcentral.com/submit 